\title{
Appendicular Mass in Children: Our Experience with Early Appendectomy
}

\author{
RADI ELSHERBINI, M.D.* and TAHA ALKHATRAWI, M.D.** \\ The Department Pediatric Surgery, Faculty of Medicine, Mansoura University, Egypt* and \\ Medina Maternity and Children Hospital, Medina, KSA**
}

\begin{abstract}
Acute appendicitis remains the commonest cause of acute abdomen in children with appendicular mass as one of its common sequelae. Management of these cases can be surgical or via a conservative approach. Our study aims to express our experience as regarding the feasibility and outcome of early surgical intervention of appendicular mass in children.
\end{abstract}

Patients and Methods: Our study included 48 cases of fixed appendicular mass, diagnosed by clinical examination and radiological investigations. Early surgical intervention were done for these cases either by laparoscopic or open approach. The operative complications, post-operative course, hospital stay and follow-up data were assessed.

Results: In this study, 48 patients were included (26 females and 22 males), their ages ranged from 4 to 12 years with the mean age was 7.8 years. Open appendectomy was done in 34 patients and laparoscopic approach in 14 cases with conversion of two cases from laparoscopy to open approach. Symptoms and signs included vomiting, fever, abdominal pain, tenderness and palpable abdominal mass. Appendicular mass formed of bowel loops and omentum without pus formation was detected in $42(87.5 \%)$ patients while localized pus collection in the mass was detected in 5 (10.4\%) patients and frank appendicular abscess was detected in 1 patient $(2.08 \%)$. Bowel injury happened in two cases $(4.2 \%)$, diagnosed and managed intraoperatively and passed smoothly. Residual pus collection occured in 4 cases (8.4\%). Two cases treated conservatively, while laparoscopic drainge cured the other two. Wound infections had occurred in 8 cases $16.6 \%)$. These cases were treated by IV antibiotics. Two case needed drainge and the wound layers were dissected.

Conclusion: Early surgical intervention of appendicular mass in children is safe, effective and reliable approach with good outcome and low rate of complications.

Key Words: Appendicular mass - Lanz incision - Laparoscopic appendectomy.

\section{Introduction}

ACUTE appendicitis in the most common intra abdominal condition requiring surgery in children

Correspondence to: Dr. Radi Elsherbini, E-Mail: Radyawad72@yahoo.com
[1]. Appendicular mass results from appendicitis and abscess is a localized suppurative process that complicates the mass [2]. Treatment of appendicular mass in children is controversial with two schools of management [3]. First, initial nonoperative management and second treatment is early surgical intervention. Nonoperative management with antibiotics has been shown to be safe and effective in these situations with debates about long hospital stay, the need for repeated laboratory and radiological studies and the need for appendectomy for failed and recurrent cases [4]. Early surgical intervention has been raised to minimize these complications with better results, especially if performed with meticulous dissection and safe procedure [5]. The aim of our study is to put highlights on the efficacy and outcome of early surgical intervention of appendicular mass in children.

\section{Patients and Methods}

This is a retrospective study of 48 cases of fixed appendicular mass, diagnosed and operated in Pediatric Surgery Department Medina Maternity and Children Hospital Medina, KSA. This study was performed during the period between Feb. 2011 and Dec. 2019. Ethical committee of our hospital approved this study. Diagnosis of these cases were confirmed by clinical examination, laboratory investigations, radiological studies (abdominal ultrasound with or without CT) and in some cases examination under general anaesthesia. Laboratory investigations included CBC, ESR CRP, urea and electrolytes. Operative intervention was done by open appendectomy or laparoscopic appendectomy. Age and sex, duration of symptoms, findings at initial examination operative details, complications and length of hospital stay were analyzed for each patient. Fig. (1) appendiceal mass with amulgamated bowel loops around an inflammed appendix with free fluid in the pelvis. 


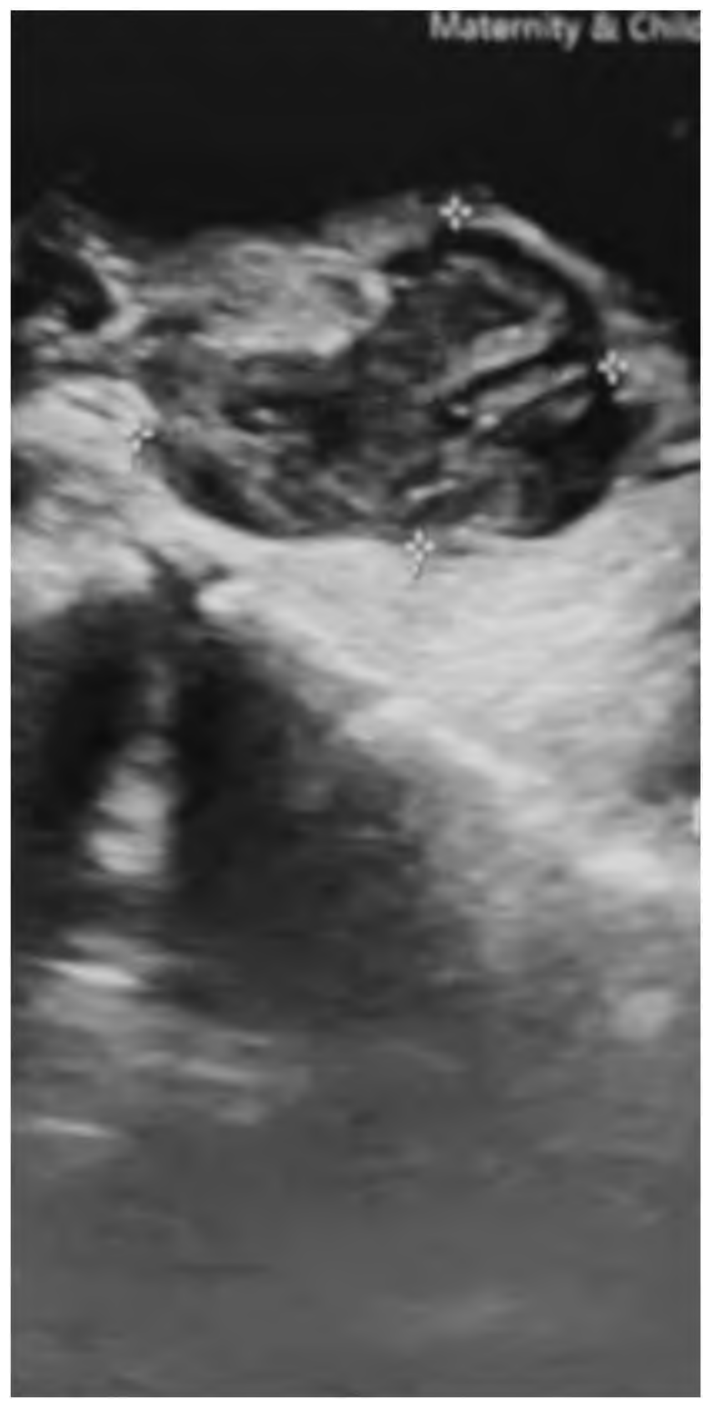

Fig. (1): Showed the ultrasonographic features of appendicular mass in a child aged 8 years with inflamed appendix surrounded by omentum and bowel loops.

Patients underwent operation within 24-48 hours of admission after preliminary investigations, good hydration and family counseling.

Open or laparoscopic approach was used. The open procedure were done for 34 cases while the laparoscopic approach was used in 14 patients.

The open procedure was done through Lanz incision. Dissection of the inflammatory mass from the surrounding healthy tissues and appendectomy was done. If pus was detected, a good lavage and irrigation of the peritoneum was performed.

A drain was inserted around the area of the mass and into the pouch of Douglas in some selected cases with huge abscess cavity or excess dissection was done.
During the laparoscopic approach, the peritoneal cavity was accessed via umbilical insertion of a $10 \mathrm{~mm}$ trocar. Two additional $5 \mathrm{~mm}$ trocars are inserted in the supra-pubic and left iliac fossa regions. A careful dissection is employed to release the appendix from adherent omentum or loops of bowel, using a blunt non traumatic instrument and ultrasonic dissector which was also used to divide the mesoappendix. The appendix was divided at the base after two end loop application and extracted through the umbilical port with removal of the trocar itself with the appendix to avoid direct contact with subcutaneous tissue and umbilical skin. Good irrigation with warm saline and adequate suction was done.

Patients started oral fluids within 24-48 hours and discharged from the hospital after 2-5 days. Antibiotics were given IV during the hospital stay (third generation cephalosporins and metronidazole was added if pus was found) and then oral continuation of the antibiotics for additional three days after discharge. Follow-up visits were conducted 1, 3 and 6 months post-operative, detecting possible late complications.

\section{Results}

In this study, 48 patients were included 22 males $(45.8 \%)$ and 26 females $(54.2 \%)$. Their ages ranged from 4 to 12 years with the mean age was 7.8 years. This study was conducted from Feb. 2011 to Dec. 2019. The symptoms of the patients included localized or generalized abdominal pain in 46 cases $(95.8 \%)$, vomiting in 44 cases $(91.6 \%)$, fever in 39 cases $(81.3 \%)$, diarrhea in 12 cases $(25 \%)$ and dysuria in 6 cases $(12.5 \%)$. In addition, abdominal tenderness and rigidity were detected in 36 cases (75\%), palpable fixed appendicular mass in 35 cases (72.9\%) and leukocytosis in 42 cases $(87.5 \%)$. These symptoms ranged from 2 to 5 days in duration. Abdominal ultrasound confirmed the diagnosis in all of these cases while 9 cases $(18.7 \%)$ were diagnosed by abdominal ultrasound and abdominal CT. These cases were presented to our institute with abdominal CT after the ultrasound study to confirm the diagnosis. Only 4 cases $(8.4 \%)$ were detected during the usual appendectomy for uncomplicated appendicitis, in which examination under general anaesthesia revealed the presence of appendicular mass.

Open appendectomy was done in 34 patients $(70.9 \%)$ while laparoscopic approach was performed in 14 patients $(29.1 \%)$. Conversion from laparoscopic to open procedure occurred in two cases. This happened because of difficulty in dis- 
section and failure to get the appendix. During the open technique, we need to extend our incision in 9 cases. Seven cases were due to difficult dissection, huge pus amount and occurrence of multiple serosal tears. The other two cases, were because of caecal injury to do proper bowel examination and to manage the injury carefully. Mean operative time was lower in laparoscopic surgery compared to open surgery (65.5 and 76.4 minutes respectively).

Appendicular mass formed of bowel loops and omentum without pus formation was detected in 42 patients $(87.5 \%)$ while localized pus collection in the mass was detected in $5(10.4 \%)$ patients and frank appendicular abscess was detected in 1 patient (2.08\%). Table (1) shows operative, early and late post-operative complications.

Table (1): Operative, early and late post-operative complications.

\begin{tabular}{lcl}
\hline & No. of cases & $\%$ \\
\hline Bowel injury & 2 & 4.2 \\
Multiple serosal tears & 11 & 22.9 \\
Wound infection & 8 & 16.6 \\
Residual pus collection & 4 & 8.4 \\
Adhesive intestinal obstruction & 6 & 12.5 \\
\hline
\end{tabular}

Bowel injury occurred in two cases. Both of them were during the open procedures and during the early period of the study. Both cases were detected intraoperatively. We extended the incision in both of them. The aim for this was to do good suctioning, irrigation and manage the perforation properly. The two were caecal injury, in its anterior wall. In the first case after good triming of the edges, the perforation was closed properly and a covering ileostomy was done. Patient did fine after that and his stoma was closed three months later. In the second case, triming of the edges was done, good peritoneal toilet and insertion of folley catheter in the fistula to act as a temporary diverting manouver till the perforation is closed. We observed the patient very well post-operatively. He did fine. Five days later, no more drainage from the catheter, passing motion regularly and started oral feeds. Follow-up abdominal ultrasound confirmed no collection, catheter was removed and patient discharged in good condition.

Residual pus collection was noticed in four cases. Two cases improved with intravenous antibiotics within five days. The other two patients did not improve after three days of treatment and required laparoscopic drainage, after which their symptoms subsided and discharged in good condition after a period of 7 and 9 days post-operatively.

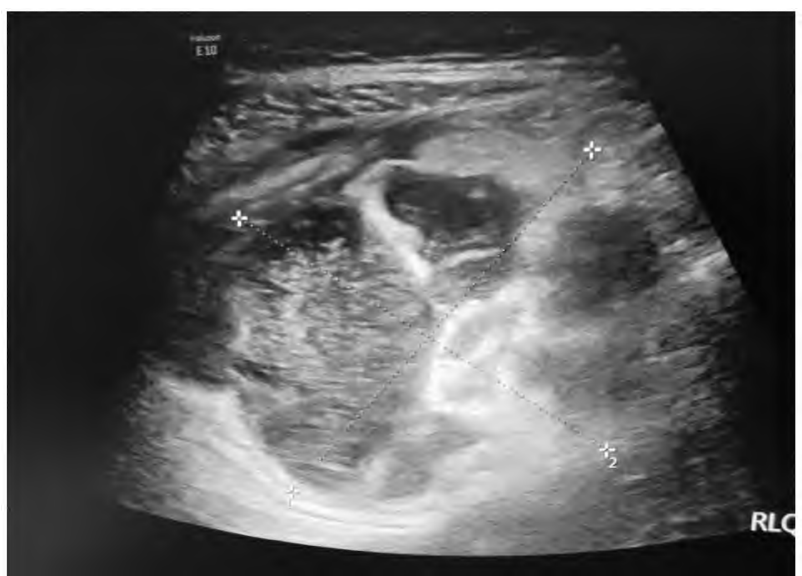

Fig. (2): Shows a marked residual pus collection that required a laparoscopic drainage.

Wound infections had occurred in 8 cases $(16.6 \%)$. Two of these cases were from the laparoscopic group and had infection in the umbilical port via which the appendix was removed. These cases responded well to medical therapy in two days. The other six cases were from the open group that needed extension of their wounds. Four of them responded also very well to IV antibiotics in four days. The last two cases developed infection with discharge of pus from the deep layers of the wound. In addition to IV antibiotics, we needed to open the layers of the wound and do daily dressing for five days. Finally, the infection subsided and patients discharged in good condition.

Adhesive intestinal obstruction occured in six cases. These cases included the two patients with bowel injury, two patients needed drainage for residual abscesses and two cases with multiple serosal tears. Symptoms of intestinal obstruction in these cases developed within periods of 6-18 months post-operatively. All of them responded to conservative management and discharged in good condition with no recurrence of these problems.

\section{Discussion}

Acute appendicitis remains the commonest cause of acute abdomen in children. When patients presenting late in the course of acute appendicitis they may be complicated by the development of an inflammatory mass in the right iliac fossa [6].

The inflammatory mass in most of cases consists of the inflamed or the oedematous appendix surrounded by greater omental adhesions. In some cases localized appendicular perforation results in abscess formation, or the abscess may develop within the inflammatory mass [1].

Treatment of appendicular mass is controversial and there are different options for management. 
Originally, those patients are managed conservatively followed by interval appendectomy later on. However, some surgeons have questioned the need for routine interval appendectomy in these patients unless acute appendicitis recurs $[7,8]$. This way of treatment was based on the fact that an early appendectomy in these cases is risky, time consuming and may lead to life threatening complications such as bowel injury [9].

But, there are many debates about the conservative management of appendicular mass in children. The non-operative management of patients presenting with an appendicular mass is not always successful. Authors estimate about $20 \%$ of such patients fail to respond and require a delayed and potentially more difficult appendectomy with and possible bowel resection [10]. Moreover, approximately $50 \%$ of patients may suffer a recurrence of their appendicitis or appendicular mass following discharge from hospital. This high rate of recurrence may be explained by the fact that the appendix is not atrophied and its lumen is not obliterated in all cases [11].

A large number of patients may lose their follow-up visits or even refuse readmission for surgery once their acute problem is solved. Another disadvantage of the conservative management is the chance of misdiagnosis (nearly 15\%) in conditions such as intussusception, Meckel diverticulum, or caecal masses that may be treated conservatively by mistake adding a considerable morbidity [12].

Also, the conservative treatment comprises hospitalization, intravenous fluids, antibiotics, analgesics and a strict watch on the vitals and general state of the patient [13].

Recently, some surgeons start to go for a definite operative intervention during the primary admission [14]. Studies favoring immediate appendectomy claim an early recovery and complete cure during the same admission, avoiding the need for readmission for interval appendectomy and immediate exclusion of other pathology [15].

The only argue with this early surgical intervention is that, in the presence of appendix mass, appendectomy can be technically difficult, and intraoperative complication rates may rise. The most common complications include intestinal injury, wound infection, intraabdominal abscess, enteric fistula, and respiratory complications. The rate of these complications is considered low in most of the literatures. This can be explained by the new era of laparoscopic experience and sur- geons care during dissection of the appendix from its adherent $[15,17]$.

Apart from the two cases of bowel injury-that passed smoothly-our study showed a high success rate in managing cases of appendicular mass in children by early surgical intervention either by open or laparoscopic approach.

Our study agree with the study of Samuel et al., [2] who stated that surgical intervention was beneficial over non-operative management in their cohort of patients. They did their study on 25 cases of fixed appendicular mass. The mean length of hospital stay after appendectomy was 4.80 .4 days. All cases received intravenous antibiotics for 4.8 0.4 days and completed a 5-day course by oral medication. Only four cases of wound infection were documented as post-operative complications. Three of them were treated with oral antibiotics, and one needed drainage under general anesthesia. No other post-operative complications or significant sequelae were seen after early open appendectomy.

Our study agreed also with the study of Brian et al., [5] who documented no significant postoperative complications in their study, apart from relatively long operative time (103min), prolonged time to ambulation (median two days), increased time to resumption of diet (median 4 days) and relatively long post-operative stay (median 6 days). The study was done on 22 cases of appendicular mass in children. They explained this success by careful and meticulous dissection during surgery.

Vikesh et al., [18], did their study on 48 cases. They did early surgical intervention of these cases with appendicular mass. The results agree with our study and were encouraging. They reported operative time 72 minutes (range 45-93). Complications happened in 4 cases only (7.69\%), including three cases of wound infection and one case with pelvic abscess that needed percutaneous aspiration. They put their conclusion that early surgical intervention of appendicular mass in children is a safe, effective and reliable procedure and avoids situations of misdiagnoses and argues of nonoperative treatment.

On the other hand, Erdogan et al., [3]. Did their study as a comparison between early surgical intervention of appendicular mass and the conservative approach. They early operated 19 patients of appendicular mass, with a hospital stay of $8.7 \pm 3.2$ days. They documented a rate of complications (26.3\%), including two cases of ileal injury. An intra-abdominal abscess developed in the one patient. They explained these complications by inability to identify the appendix, intraoperative 
extensive dissection to release the adhesions around the appendix, bleeding and subsequent bowel injury. Also they stated that the persistence of adhesions at interval appendectomy was significant in the group managed by non-operative treatment of appendiceal mass followed by interval appendectomy. In the light of their experience Erdogan et al., recommended conservative treatment followed by elective appendectomy in patients with an appendix mass. Erdogan et al., stated the most important criteria for immediate operation were a failure to respond to medical treatment and suspicion of another diagnosis.

In conclusion, early surgical intervention of appendicular mass in children either by open appendectomy or laparoscopic approach can be considered as a safe, effective and reliable technique. It helps to avoid a lot of disadvantages of the conservative procedure. To minimize the possible complications of this approach, carful, meticulous dissection should be followed strictly by the operating surgeon, proper use of antibiotics and good postoperative follow-up.

\section{Conclusion:}

Early surgical intervention of appendicular mass in children is a safe, feasible and effective approach with less complications and short hospital stay. Better results can be achieved by proper diagnosis and intraoperative meticulous dissection.

\section{Conflicts of interest:}

None.

\section{References}

1- PAOLA FUGAZZOLA, FEDERICO COCCOLINI, MATTO TOMASONI, MARCELLO STELLA and LUCA ANSALONI: Early appendectomy VS. conservative management in complicated acute appendicitis in children: A meta-analysis. Journal of Pediatric Surgery, 54: 2234-41, 2019.

2- SAMUEL M., HOSIE G. and HOLMES K.: Prospective evaluation of nonsurgical versus surgical management of appendiceal mass. J. Pediatr. Surg., Jun., 37 (6): 882-6, 2002.

3- ERDOGAN D., KARAMAN I., NARCI A., KARAMAN A., CAVUSOGLU Y.H., ASLAN M.K., et al.: Comparison of two methods for the management of appendicular mass in children. Pediatr. Surg. Int., 21: 81-3, 2005.

4- DEVIN PUAPONG, STEVEN L. LEE, PHILIP I. HAIGH, et al.: Routine interval appendectomy in children is not indicated. Journal of Pediatric Surgery, 42: 1500-3, 2007.
5- BRIAN K.P. GOH, CHAN-HON CHUI, TE-LU YAP, YEE LOW, THICHEN K. LAMA, et al.: Is early laparoscopic appendectomy feasible in children with acute appendicitis presenting with an appendiceal mass? A prospective study. Journal of Pediatric Surgery, 40: 11347, 2005.

6- M.A. BAHRAM: Evaluation of early surgical management of complicated appendicitis by appendicular mass. International Journal of Surgery, 9: 101-3, 2011.

7- EIN S.H. and SHANDLING B.: Is interval appendectomy necessary after rupture of an appendiceal mass. Journal of Pediatric Surgery, 31: 349-50, 1996.

8- KARACA I., ALTINTIPARK Z., KARKINER A., et al: The management of appendiceal mass in children: Is interval appendectomy necessary? Surg. Today, 31: 6757, 2001.

9- RUSSEL R.C.G. and WILLIAM N.S.: Vermoform appendix. In: Short practice of surgery; $24^{\text {th }}$ edition; (2) pp. $1203 \mathrm{e} 8,2004$.

10- JORDAN J.S., KOVALCIK P.J. and SCHWAB C.W.: Appendicitis with apalpable mass. Ann. Surg., 193: 2279, 1981.

11- GAHUKAMBLE D.B. and GAHUKAMBLE L.D.: Surgical and pathological basis for interval appendicectomy after resolution of appendicular mass in children. J. Pediatr. Surg., 35: 424-7, 2000.

12- PSP, BHATTACHARYA D. and AMORI B.J.: Early laparoscopic appendectomy for appendicular mass. Surg. Endosc., 16 (12): 1783-5, 2002.

13- YUJIRI TANAKA, HIROO UCHIDA HIROSHI KAWASHIMA, et al.: Long-term outcomes of operative versus nonoperative treatment for uncomplicated appendicitis. Journal of Pediatric Surgery, 50: 1893-7, 2015.

14- OKUNE G., MAREK and JAROS1AW K.: Management of appendiceal mass In Children and adults: Our experience. Internet J. Surg., 9 (2), 2007.

15- XIAOLIN WANG, WEN ZHANG, XIAOJIN YANG, et al.: Complicated appendicitis in children: Is early laparoscopic appendectomy appropiate? A comparative study with the open appendectomy-our experience. Journal of Pediatric Surgery, 44: 1924-27, 2009.

16- ARSHAD MALIK, AZIZ LAGHARI A., QASIM MALLAH and ALTAF HUSSAIN TALPUR K.: Early appendicectomy in appendicular mass Da Liaquat University Hospital Experience. J. Ayub. Med. Coll Abbottabad, 20 (1), 2008.

17- GHOSH S. and De U.: Acute appendicectomy for appendicular mass: A study of 87 patients. Ceylon Med. J., 47 (4): 117-8, 2002.

18- VIKESH AGRAWAL, HIMANSHU ACHARYA and DHANANJAYA SHARMA: Early laparoscopic management of appendicular mass in children: Still a taboo, or time for a change in surgical philosphy? Journal of Minimal Access Surgery, 12 (2): 98-101, 2016. 


\section{عرض لخبرتنا فى علاج كتلة البطن الناتجة عن إلتهاب الزائدة الدودية

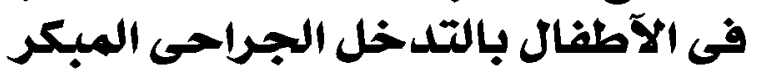

يعد إلتهاب الزائدة الدودية فى الآطفال هو آكثر الآسباب شيوعاً للإلتهابات البطن الحاده وكذلك المضاعفات الناتجة عنها مثل خراج البطن آو كثلة البطن الحاده في الآطفال.

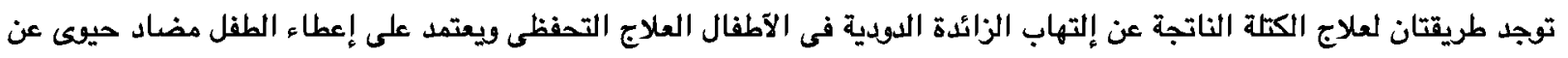

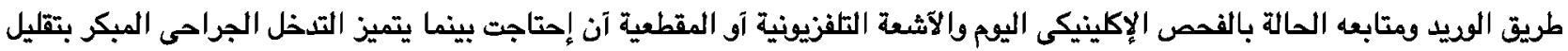

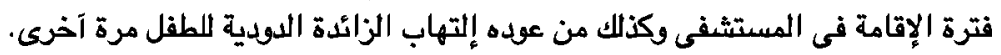

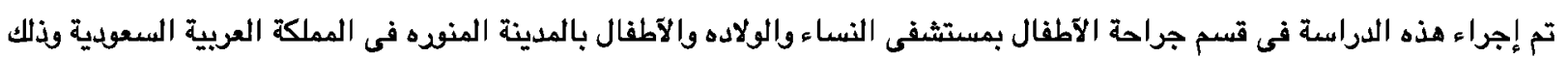

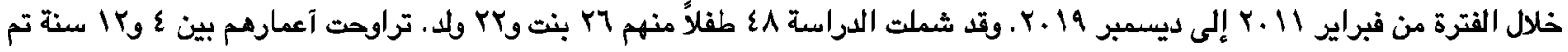
إجراء اللتدخل الجراحى المبكر في كل الحير الحالات.

كان التدخل الجراحى المفتوع فى عץ حالة والمنظار الجراحى فى عا حالة. كانت المضاعفات عبارة عن إصابة لحالة للآمعاء فى حالتين فقط وتم علاجهم تحفظياً. يمكن القول بآن التدخل الجراحى المبكر لكتلة البطن الناتجة عن إلتهاب الزائدة الدودية في الآطفال يعد طريقة آمنه وموثوقة خاصة إذا تم

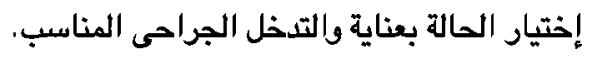

